\title{
TEKNIK ARSIR DAN PROSES MENGGAMBAR DENGAN MEDIA PENA
}

\author{
Lintang Widyokusumo \\ Visual Communication Design, School of Design, BINUS University \\ Jln. K.H. Syahdan No. 9, Palmerah, Jakarta Barat 11480 \\ lintangw@binus.edu
}

\begin{abstract}
Pen is one of the tools for an artist or designer in expressing ideas in visual form. Strong character of the pen scratch has a special attraction in the diversity of drawings style. It requires a long process for an artist to find the distinctiveness in a pen scratch with full of confidence. Besides determining the choice of the type of pen that will be used, the choice of the type of hatching used also determines the identity of signature scratch in the drawing. Referring to the strong character of a pen scratch as a preliminary sketch of a work, a great artist and designer will produce great masterpiece that will be in a work of painting, sculpture and visual communication design. Research methodology study uses data collection techniques from some of the literature, observations, and analysis of different forms of shading and its influence on the results of the drawing. Research results can be used as a template for the development of the media pen drawing techniques.
\end{abstract}

Keywords: pen, illustration, hatching, ink

\begin{abstract}
ABSTRAK
Pena adalah salah satu alat bantu bagi seorang artis maupun desainer dalam menuangkan ide-ide karyanya dalam bentuk visual. Kekuatan karakter goresan pena mempunyai daya tarik tersendiri dalam keragaman karakter gambar. Membutuhkan proses yang panjang bagi seorang artis untuk menemukan goresan pena yang penuh percaya diri dan berkarakter. Selain menentukan pilihan jenis pena yang akan digunakan maka pilihan jenis arsiran yang digunakan akan menentukan jati diri goresan dalam karya gambarnya. Berangkat dari kekuatan karakter goresan pena sebagai sketsa awal sebuah karya, seorang artis dan desainer besar akan menghasilkan karya-karya besar berikutnya yang akan tertuang dalam karya lukisan, seni patung dan desain komunikasi visual.Metode penelitian ini menggunakan teknik pengumpulan data dari beberapa literatur, pengamatan, dan analisa tentang macam bentuk arsiran serta pengaruhnya terhadap hasil gambar. Hasil penelitan dapat digunakan sebagai pola dasar untuk pengembangan teknik gambar media pena.
\end{abstract}

Kata kunci: pena, ilustrasi, arsiran, tinta. 


\section{PENDAHULUAN}

Sebuah karya gambar adalah karya seni yang seperti menulis puisi indah ataupun nyanyian merdu seorang biduan. Menggambar adalah salah satu bentuk komunikasi yang tercipta ke permukaan sebagai sebuah ekspresi, observasi dan gambaran perasaan yang terdalam seorang artis maupun desainer. Ekpresi ini digunakan sebagai alat komunikasi visual untuk mengungkapkan ide-ide kepada target yang dituju.

Sebagai media komunikasi, maka artis ataupun desainer harus menguasai beberapa teknik gambar yang mumpuni yang disesuaikan dengan konsep dan karakter komunikasi yang diharapkan sehingga dapat memberikan reaksi positif bagi target audience. Pada proses awal latihan menggambar dimulai dengan latihan menggambar dengan meniru sebuah hasil fotografi. Setelah memahami proses meniru hasil fotografi kemudian dapat diaplikasikan pada tahap menggambar observasi langsung pada objek hidup di lapangan.

Ada beberapa alasan mengapa sebuah gambar diciptakan, yaitu gambar sebagai proses brainstorming, keperluan riset mengumpulkan informasi, keperluan diagram, bahan teori struktur anatomi, memperbanyak untuk tujuan pembelajaran, alat presentasi dan murni dan pemuasan estetika pribadi (Stanyer, 2003). Dalam penuangan gambar sebagai ekspresi, seorang artis atau desainer membutuhkan teknik gambar yang bervariasi. Banyak media gambar yang tersedia seperti crayon, charcoal, pensil, tinta, cat air, acrylic, cat minyak, pena dan lain-lain. media mempunyai ciri khas dan karakteristik masing-masing. Dalam penelitian kali ini akan dibahas teknik penciptaan gambar melalui media pena sebagai media paling sederhana setelah pensil.

\section{METODE}

Metode Penelitian dalam penelitian ini menggunakan metode kualitatif, di mana peneliti melalui tahapan survei literatur dan data (sejarah teknik gambar dan arsir pena beserta jenis-jenisnya). Kemudian, dilakukan tahapan observasi terhadap berbagai jenis pena beserta karakter goresan arsiran yang dihasilkan. Selanjutnya peneliti mengaplikasikan dalam praktik menggambar di lapangan, yang kemudian menjadi bahan tulisan dalam penelitian ini.

\section{HASIL DAN PEMBAHASAN}

Hampir semua orang sudah terbiasa menggambar dengan media pensil, namun hanya sebagian saja yang terbiasa menggambar dengan pena. Ada perbedaan teknis dalam menggunakan media pensil dan pena. Pada pensil saat membuat arsiran biasanya dipengaruhi oleh tekanan pensil pada kertas saat menggores di permukaan kertas. Semakin kuat tekanan maka akan semakin gelap efek arsiran yang diperoleh. Tentunya teknik tersebut tidak dapat diaplikasikan pada media pena.

Dibandingkan dengan alat gambar lainnya seperti crayon, pensil warna, cat air, charcoal dan lain-lain, pena memang relatif lebih mudah dalam mempelajarinya. Namun dibalik kemudahan penggunaan pena ini, diperlukan teknik tertentu dalam kreasi menggores dengan alat pena ini. Diperlukan pemahaman bertahap untuk mengenal karakter dari masing-masing jenis pena yang ingin dipakai. 
Terdapat beberapa jenis pena yang dapat digunakan menggambar dengan teknik ini. Biasanya karakter pena berbeda-beda terhadap kelancaran suplai tinta pada mata pena hal tersebut dipengaruhi besar kecilnya mata pena. Terdapat bermacam jenis pena seperti ball point, fountain pen, graphic pen, drafting pen dan lain-lain. Tidak ada anjuran khusus dalam memilih jenis pena-pena tersebut, setiap artis mempunyai pilihan untuk menemukan karakter dan gaya tersendiri untuk jenis efek arsiran yang diinginkan terhadap hasil gambar. Jenis pena yang paling umum digunakan adalah drafting pen dan graphic pen, karena tersedia dalam ukuran ujung pena yang berbeda-beda sesuai dengan kebutuhan. Bila drafting pen dapat diisi ulang dengan mengisi kembali atau mengganti tabung tinta, maka graphic pen hanya dapat dipakai sekali saja.

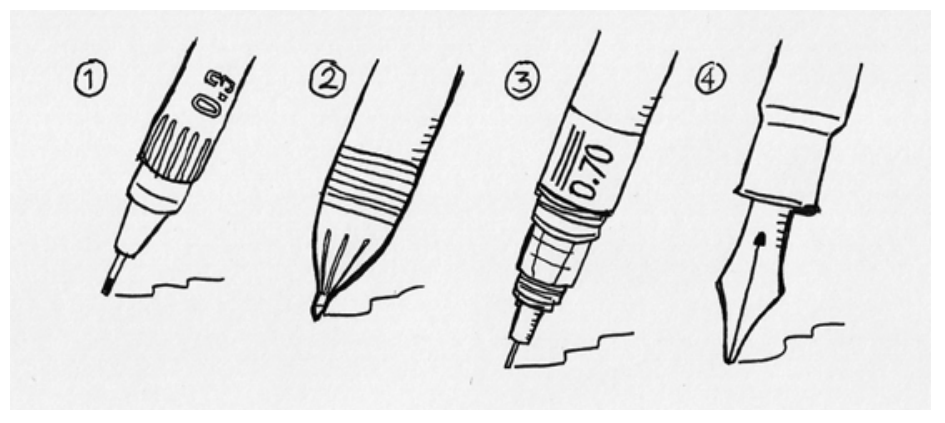

Gambar 1 Berbagai jenis pena: 1. Graphic pen. 2. Ballpoint.

3. Drafting pen. 4. Fountain pen.

(sumber: ilustrasi peneliti)

\section{Sejarah Teknik Arsir (Hatcing)}

Saat menggunakan pena, untuk menyelesaikan kontur gambar agar tercapai ilusi efek dimensi pada objek yang digambar, maka diperlukan menambahkan arsiran (hatching).Selain untuk menambahkan efek ilusi volume dan terang gelap pada benda yang digambar, arsiran juga dapat menjadi ciri khas karakter goresan seorang artis. Beberapa teknik yang biasa digunakan adalah hatching, cross hatching, contour hatching, scumbling dan stippling. Istilah ini berasal dari bahasa Perancis hachure.

Teknik arsir menggunakan pena ini sangat popular di masa Renaisans awal. Sejak tahun 1440 teknik ini menyebar dari daerah Florence, Italy hingga saat ini. Banyak pelukis dan pematung di era Renaisans menggunakan teknik ini pada sketsa awal proses mereka sebelum menuangkannya dalam lukisan ataupun seni patung. Istanto (2000) perangsang besar untuk menggambar terjadi pada jaman Renaisans setelah digunakannya kertas dalam gambar. Ketika orang Mesir membawa papyrus ke Eropa, bahan ini menjadi sangat terkenal karena lebih murah dibandingkan bahan kulit dan lebih praktis karena mudah digulung (Istanto, 2000).

Beberapa artis cartographer (perancang peta atau bentangan globe) seperti Giovanni Leardo dari Venesia menampilkan karya teknik hatching yang kompleks. Pada tahun 1450 teknik ini menyebar ke area lain seperti daerah Peninsula di Itali kemudian beberapa Negara Eropa lainnya seperti Jerman (Jess: 2008). 


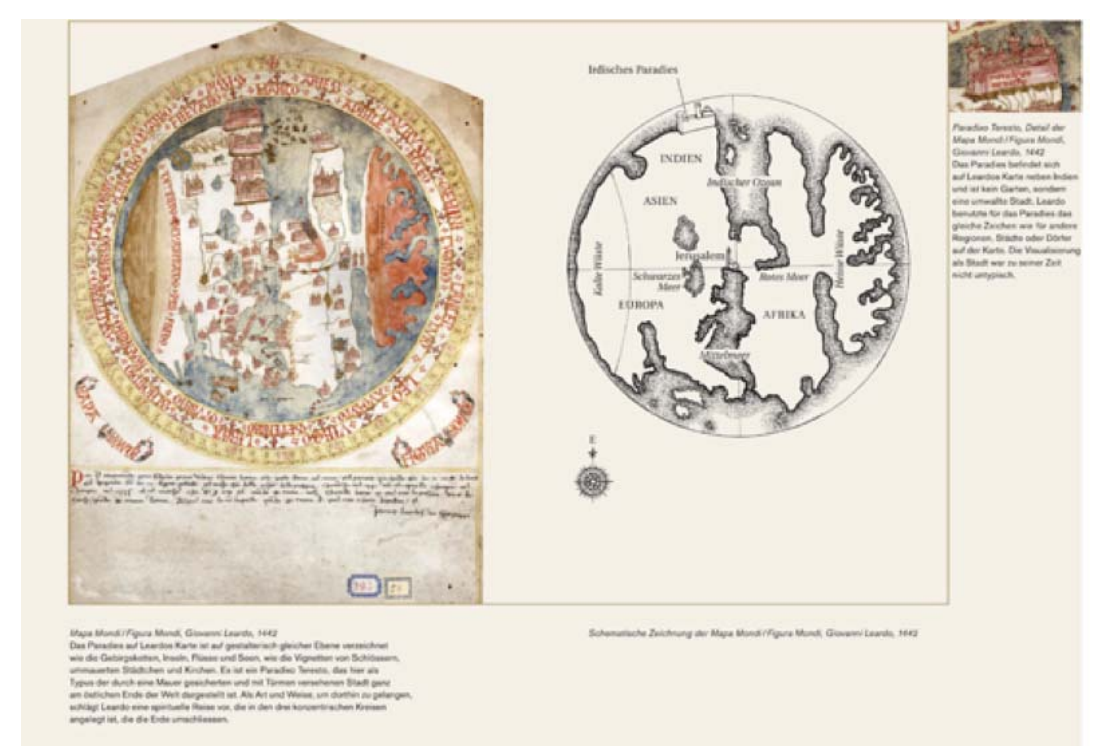

Gambar 2 Ilustrasi peta karya Giovanni Leardo (sumber: www.stylepark.com)

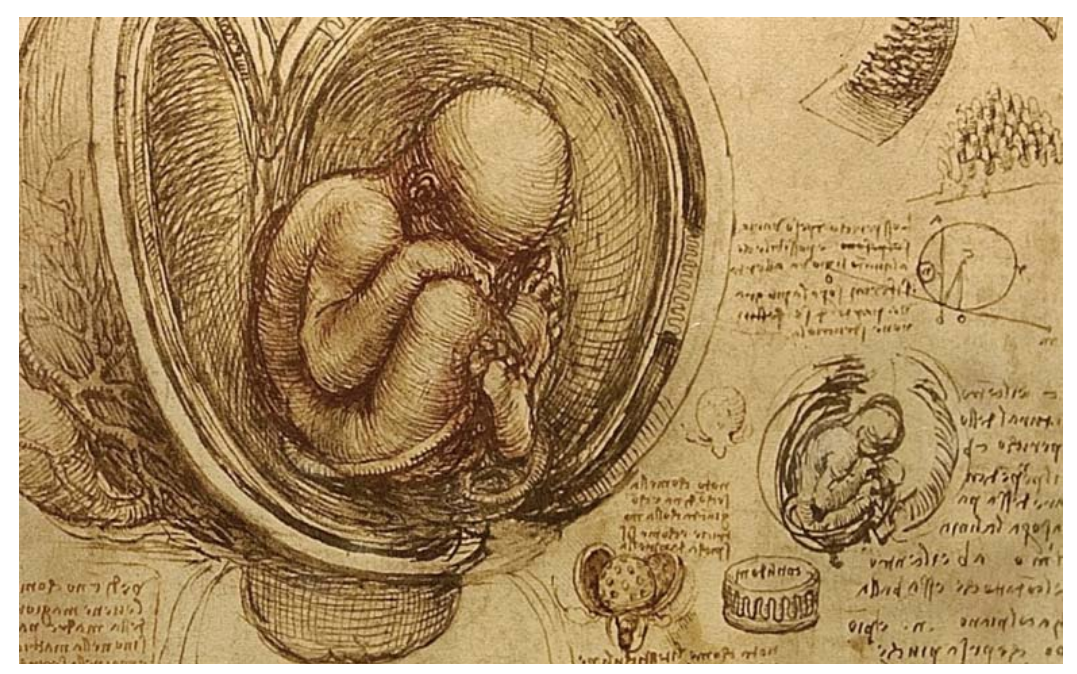

Gambar 3 Sketsa dengan arsiran pena karya Leonardo Da Vinci (sumber: dd.salgoodsam.com)

Leonardo Da Vinci adalah salah satu master dalam teknik hatching ini tergambar dalam karya-karya sketsanya menuangkan ide-idenya yang revolusioner. Berikut adalah contoh jenis goresan arsir (hatching) yang dihasilkan dari masing-masing teknik:

\section{Arsiran satu arah (hatching)}

Pada teknik ini pena digoreskan dalam arah yang sama. Sehingga terlihat barisan garis sejajar dan searah. Semakin sering kita menggores maka akan timbul efek lebih gelap karena semakin padat dan menumpuknya garis akan menambah massa garis menjadi lebih tebal sehingga terbentuk efek ilusi volume terang bayang. 


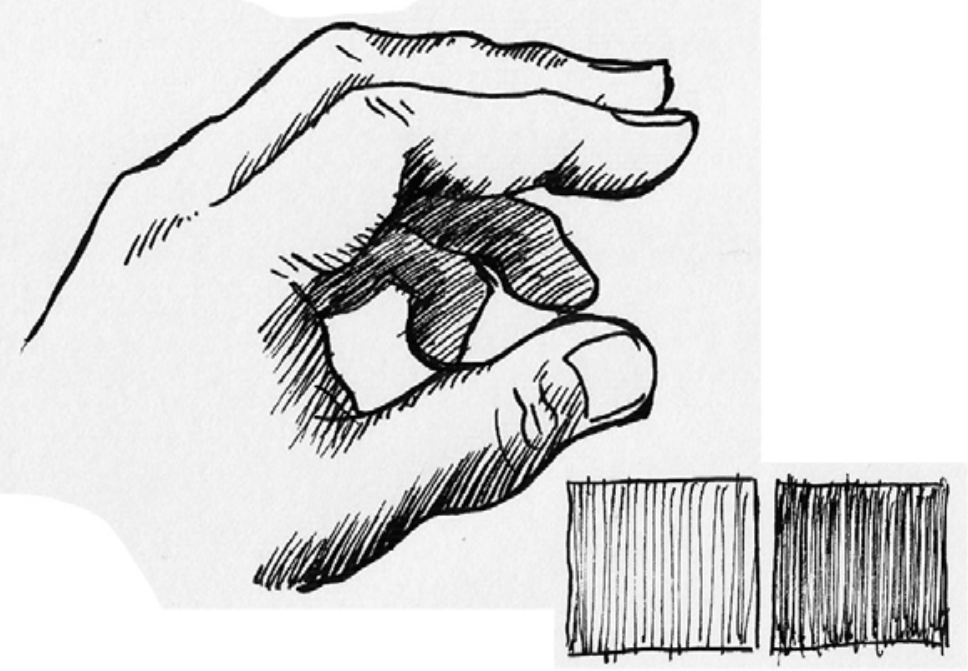

Gambar 4 Teknik arsir dengan goresan pena satu arah (sumber: ilustrasi peneliti)

\section{Arsiran silang (cross hatching)}

Teknik ini mirip dengan arsiran satu arah, namun terjadi persilangan arah dari goresan pena tersebut. Pada bagian yang ingin diarsir lebih gelap dapat juga goresan ditumpuk dengan menggunakan arah garis yang berbeda. Biasanya perbedaan arah dari garis awal ke garis berikutnya adalah 45 derajat.

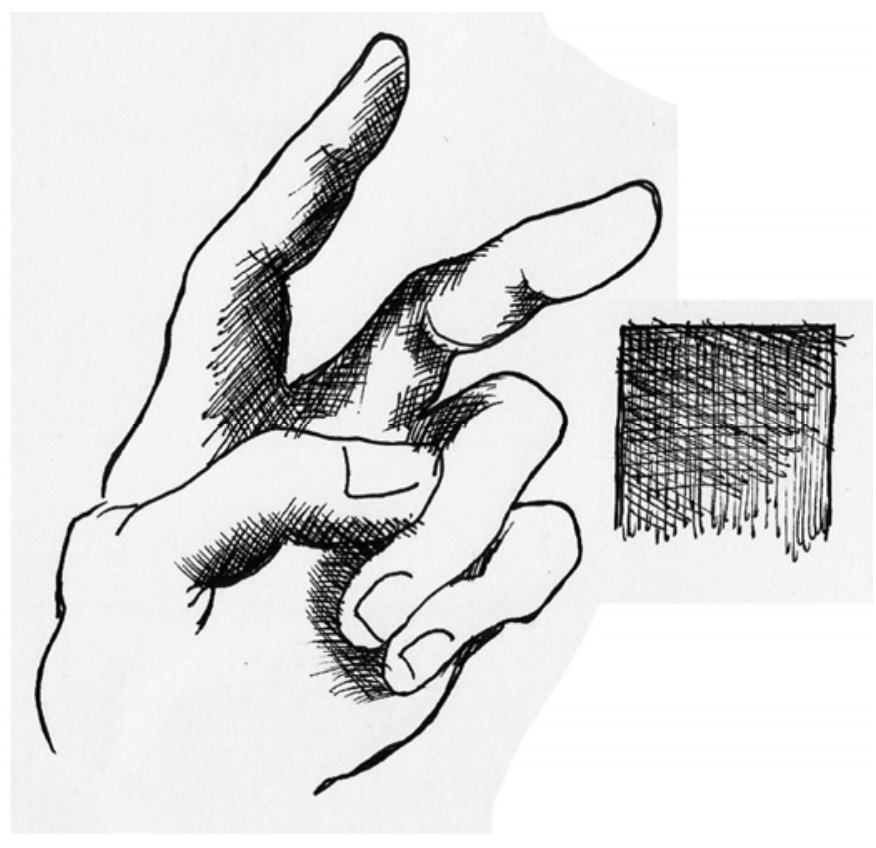

Gambar 5 Teknik arsir garis bersilang (sumber: ilustrasi peneliti) 


\section{Arsiran searah kontur (contour hatcing)}

Pada teknik ini goresan arsir pada pena mengikuti bentuk kontur bidang yang ingin diarsir, maka akan terlihat volume pada benda tersebut. Biasanya teknik ini digunakan pada menggambar figur manusia, hewan dan tumbuhan.

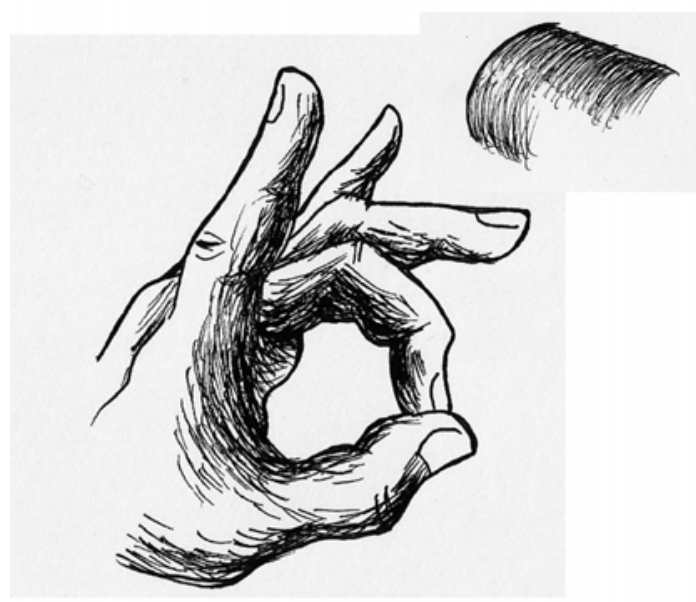

Gambar 6 Teknik arsir mengikuti kontur (sumber: ilustrasi peneliti)

\section{Arsiran coretan bebas (scumbling)}

Pada teknik ini arsiran berbentuk corat-coret bebas. Biasanya goresan tidak berupa garis namun seperti coretan bebas. Coretan bebas ini akan lebih menarik bila arah goresan dapat dirubah secara acak membentuk ilusi volume yang diinginkan.

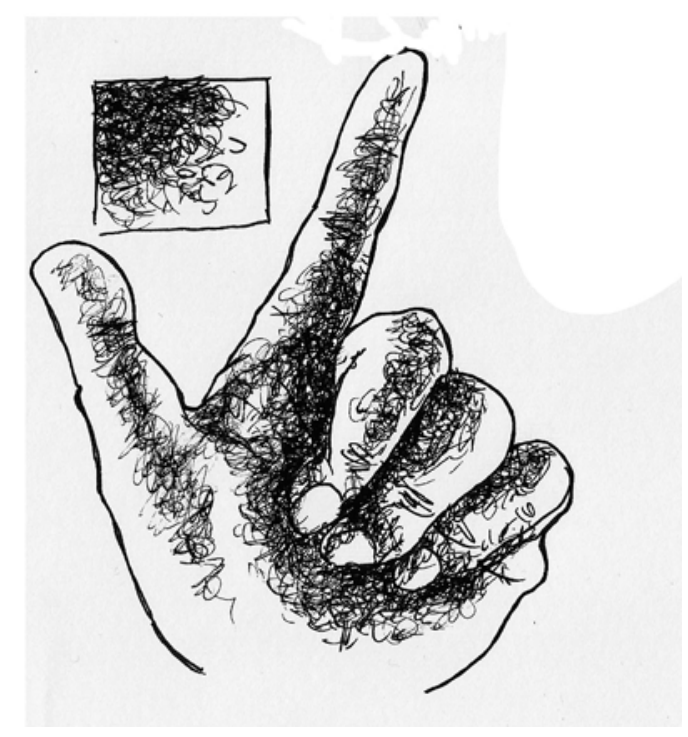

Gambar 7 Teknik arsiran coretan bebas (sumber: ilustrasi peneliti) 


\section{Arsiran titik (stippling)}

Adalah teknik arsiran dengan membuat titik-titik seperti teknik pointilisme. Semakin dekat dan rapat titik-titik yang dibuat maka semakin gelap efek yang ditimbulkan.

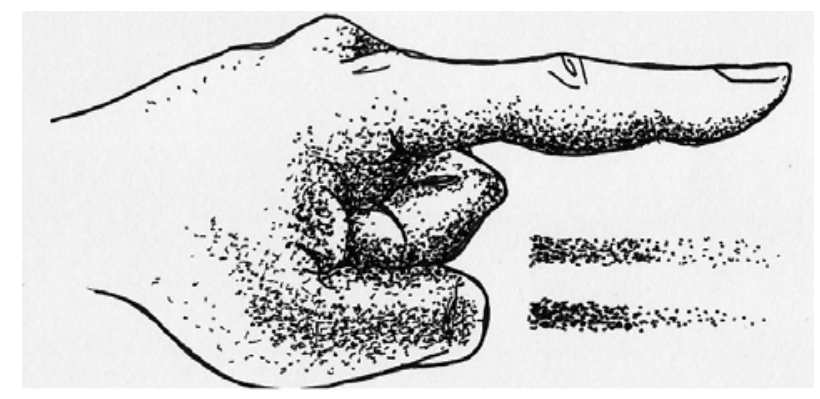

Gambar 8 Teknik arsiran memnggunakan gabungan titik-titik (sumber: ilustrasi peneliti)

Berbeda dengan menulis, saat menggambar dengan tinta maka goresan yang dilakukan lebih bebas bergerak di atas kertas. Yang perlu diingat bahwa sekali menggores tidak akan bisa dihapus, maka semakin sering kita berlatih menggores, semakin alami efek yang dihasilkan oleh pena tersebut. Teknik menggambar dengan pena ini biasanya dilakukan pada menggambar langsung secara spontan. Seorang illustrator yang memilih menggunakan media pena, memerlukan proses pengenalan media pena yang digunakan dalam rangka pencarian garis spontan, melakukan latihan menggores yang monoton dan konsisten untuk menghasilkan karakter gambar yang diinginkan.

Kunci dari menggambar dengan pena ini adalah keberanian untuk menggoreskan tarikan garis. Dibutuhkan pengalaman menggambar sebelumnya untuk mengunakan media pena ini. Sebelum menggoreskan pena, biasanya sudah terpikir komposisi elemen-elemen gambar yang akan dituangkan. Dalam proses menggambar dengan pena ini dibutuhkan suatu keberanian tarikan garis yang lurus sesuai perspektif, tarikan lengkungan yang indah, goresan benda/manusia secara spontan semua dalam satu kali gores tanpa keraguan.

Tidak hanya keberanian menggores secara spontan namun juga dibutuhkan ketekunan dan kesabaran dalam memberi arsiran. Tidak seperti karakter pensil yang dapat memenuhi bidang arsiran secara cepat dengan menggosok, ataupun cat air yang sekali menyapu kuas maka warna akan segera memenuhi bidang yang digambar. Keindahan efek yang dihasilkan dengan teknik menggambar menggunakan pena ini tidak hanya bergantung pada mutu pena yang digunakan namun juga jenis kertas yang dipakai. Kertas dengan permukaan halus dan licin seperti kertas gambar HVS tidak mudah menyerap tinta dianjurkan dalam teknik menggambar dengan pena ini.

Namun hal tersebut bukan merupakan syarat mutlak, estetika karakter yang didapat dari perpaduan jenis pena dan jenis kertas yang digunakan merupakan selera estetika masing-masing artis dalam menentukan karakter goresan pena. Seperti kertas bertekstur biasanya akan menghasilkan permukaan yang 'berbulu' bila menggunakan fountain pen, namun terkadang menghasilkan efek yang tak terduga.

Berikut adalah tahapan proses menggambar sketsa dengan pena, pertama, sebelum mulai menggambar, pilihlah sudut pemandangan yang menarik atau objek benda/figure yang unik. Coba untuk memilih titik pusat perhatian yang menarik dari keseluruhan pemandangan yang ada. Pemilihan pusat perhatian atas pertimbangan komposisi yang menarik dari elemen-elemen yang ada seperti misalnya bangunan tua yang unik di antara gedung pencakar langit, mobil antik di antara hiruk pikuk 
sebuah pasar, pohon beringin di tengah taman kota dan lain-lain. Sehingga objek yang akan digambar mendapatkan sudut yang lebih fokus, menarik dan detail.

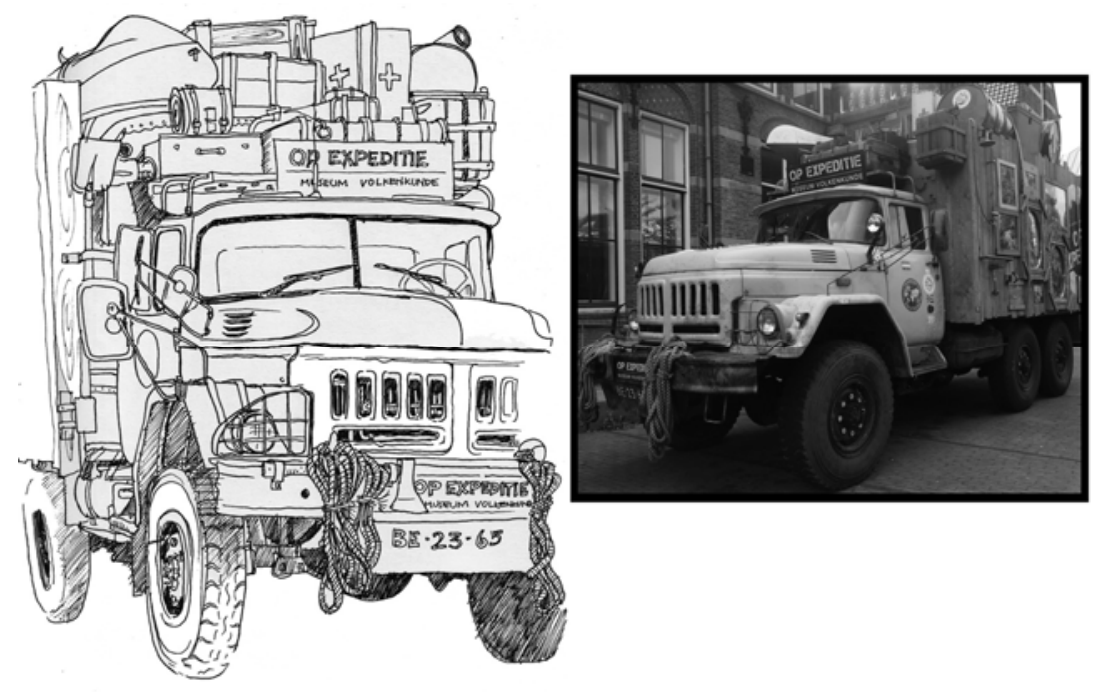

Gambar 9 Tentukan objek dan angle menarik sebelum memulai menggambar (sumber: ilustrasi peneliti)

Kedua, setelah menentukan sudut yang akan digambar, letakkan sehelai kertas di bawah tangan agar kertas gambar bersih dari keringat yang dapat merusak gambar akibat tinta yang belum kering benar. Mulailah menggambar dengan posisi pena yang dirasakan nyaman dalam genggaman tangan, sehingga pena bebas bergerak secara spontan. Ketiga, cobalah untuk berlatih menorehkan garis panjang sebagai kontur dengan percaya diri pada bentuk-bentuk geometris. Rasa percaya diri seorang illustrator media pena ini akan terlihat jelas pada karakter garis yang dihasilkan. Setelah itu cobalah menoreh garis dengan struktur organik pada bentuk-bentuk organik seperti figur manusia, hewan atau tumbuhan.

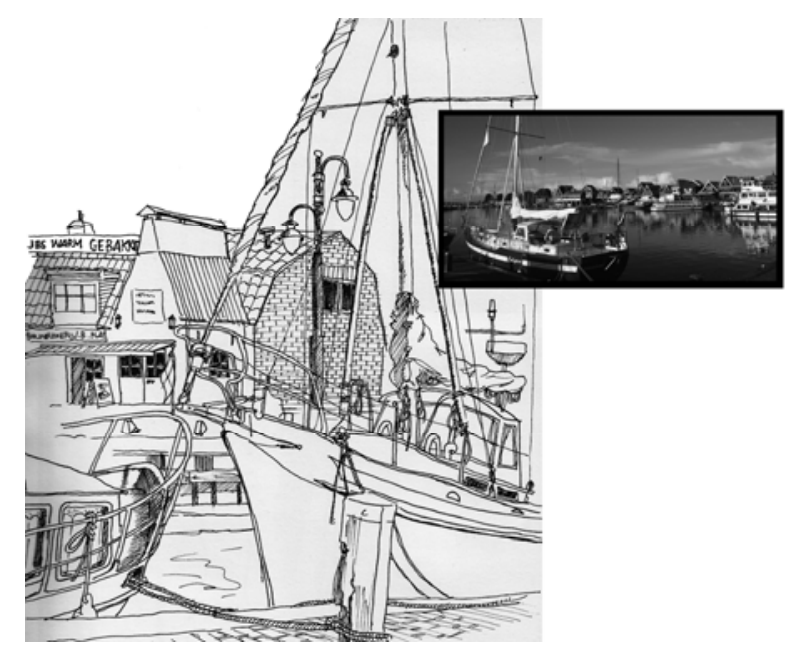

Gambar 10 Tarikan garis tegas dan percaya diri memerlukan latihan terus menerus dalam menggambar dengan teknik pena ini (sumber: ilustrasi peneliti) 
Keempat, setelah menangkap seluruh komposisi yang diinginkan dalam frame yang sudah direncanakan, maka mulailah untuk menambahkan efek dimensi dengan menggunakan teknik arsiran seperti hatching, scumbling, dan stippling. Di sini ketekunan sangat dibutuhkan untuk mendapatkan efek ilusi dimensi gelap terang yang diinginkan, dengan menorehkan arsiran secara bertahap. Untuk menggambar sebuah panorama pemandangan kota maupun pegunungan akan ditemukan hirarki elemen benda pada objek gambar atau pictorial zones. Teknik arsiran yang akan menentukan apakah benda tersebut sebagai objek utama, foreground ataupun background. Untuk objek utama, arsiran akan terlihat lebih detail dibandingkan arsiran foreground dan background.

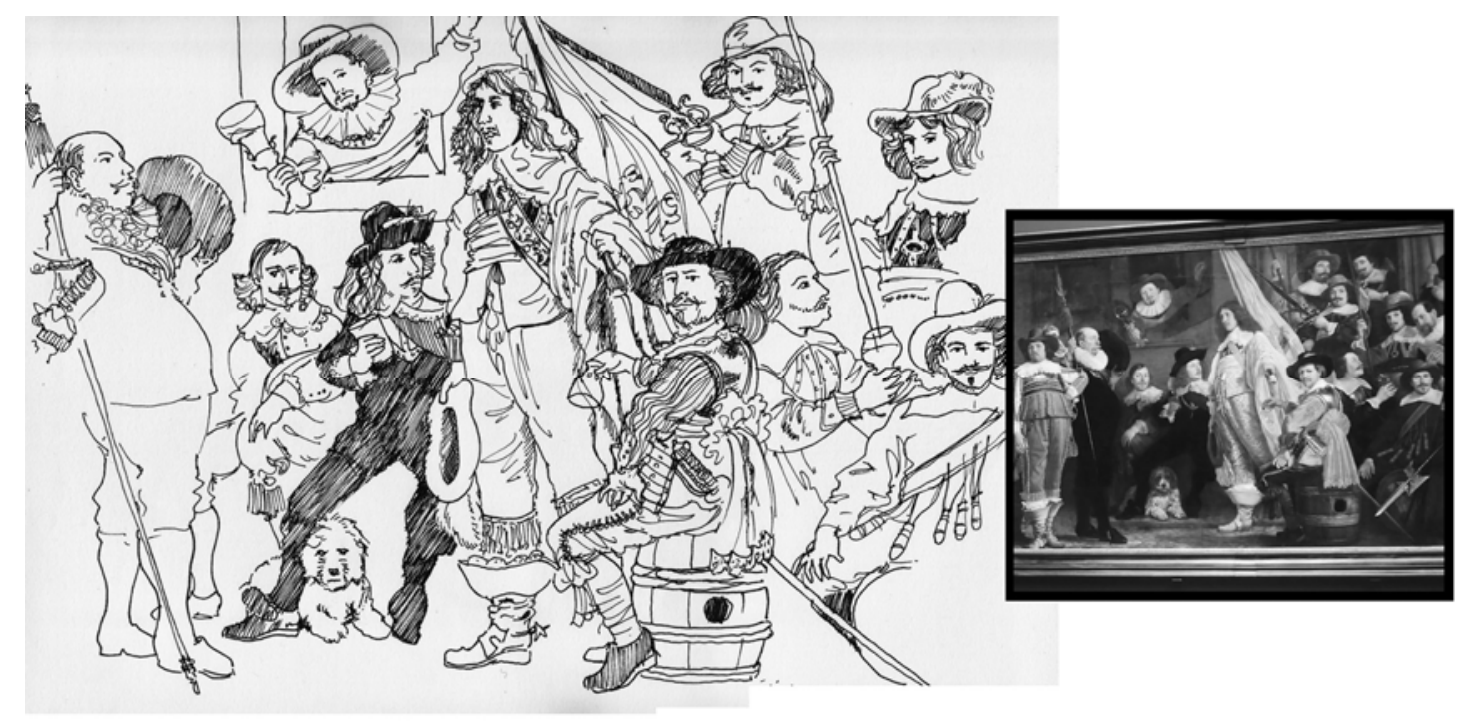

Gambar 11 Setelah keseluruhan komposisi dan kontur didapat, maka volume dimensi dapat dilakukan dengan teknik arsir yang diinginkan (sumber: ilustrasi peneliti)

\section{SIMPULAN}

Selain pensil, maka alat media paling sederhana dalam penuangan ide-ide awal adalah pena. Dengan media pena ini tahapan awal dari sebuah proses desain dapat dieksplor sebanyak-banyaknya. Bahkan beberapa karya besar artis dan desainer ternama berawal dari goresan kasar media pena seperti Leonardo Da Vinci. Teknik gambar dengan menggunakan media pena ini mempunyai karakteristik tersendiri diperoleh dari goresan spontan, percaya diri dan bahkan liar. Sekali menggores tidak akan dapat dihapus seperti media pensil, untuk itu diperlukan latihan secara menerus dan ketekunan tersendiri untuk dapat memahami karakter dari masing-masing jenis pena yang dipilih. Tidak hanya berhenti disitu saja, teknik arsir dengan pena memerlukan ketekunan dan kesabaran tersendiri bagi seorang artis ataupun desainer. Efek ilusi dimensi dengan pena hanya bisa didapat dengan goresan arsiran yang berlapis untuk menghasilkan karya yang dahsyat. 


\section{DAFTAR PUSTAKA}

Istanto, F. (2000). Gambar Sebagai Alat Komunikasi Visual. Jurnal Nirmana. 2(1): 26.

Kroll, J. (2008). The History of the Cross Hatch Drawing Technique. Diakses 20 Mei 2014 dari http://www.ehow.com/info_8693781_history-cross-hatch-drawing-technique.html

Stanyer, P. (2003). The Complete Book of Drawing Technique. London: Arcturus Publishing. 